RESEARCH

\title{
MR $T_{1}$ and $T_{2}$ relaxations in cysts and abscesses measured by 1.5 T MRI
}

\author{
UN Yilmaz*, F Yaman and SS Atilgan \\ Department of Oral and Maxillofacial Surgery, Faculty of Dentistry, University of Dicle, Diyarbakur, Turkey
}

Objectives: The main objective of this study was to make a comparison between the relaxation rates in jaw cysts and abscesses. Such a comparison should provide quantitative information for MR image analysis.

Methods: A phantom containing 20 odontogenic jaw cysts and 11 jaw abscesses was imaged with $1.5 \mathrm{~T}$ MR. $T_{1}$ measurements were performed by using a mixed sequence of inversion recovery and spin echo, while $T_{2}$ measurements were carried out by the Carr-Purcell Meiboom-Gill (CPMG) sequence. Cystic fluids and abscesses were compared statistically. Results: In cysts and abscesses, respectively, the mean $1 / T_{1}$ was $0.9355 \mathrm{~s}^{-1}$ and $0.8245 \mathrm{~s}^{-1}$ and the mean $1 / T_{2}$ was $2.4575 \mathrm{~s}^{-1}$ and $4.7073 \mathrm{~s}^{-1}$. The $1 / T_{2}$ in cysts was very highly significantly different from that in abscesses $(p=0.0001)$. Both $T_{1}$ and $T_{2}$ were linearly proportional to material contents. $T_{2}$ relaxivities $\left[26.458 \mathrm{ml}(\mathrm{g} \mathrm{s})^{-1}\right.$ for abscesses and $21.455 \mathrm{ml}\left(\mathrm{g} \mathrm{s}^{-1}\right.$ for cysts] were higher than $T_{1}$ relaxivities $\left[5.4766 \mathrm{ml}\left(\mathrm{g} \mathrm{s}^{-1}\right.\right.$ for abscesses and $10.075 \mathrm{ml}\left(\mathrm{g} \mathrm{s}^{-1}\right.$ for cysts].

Discussion: Present $T_{2}$ measurements differentiate cysts from abscesses with a confidence interval of $95 \%$. Because in vivo and in vitro image contrasts are changed by the same parameters, the $T_{2}$ findings should present valuable information for in vivo MRI. Hence the significant difference and the relaxivities may provide quantitative information for clinicians and researchers making image analyses.

Conclusion: $\quad T_{2}$ may differentiate cysts from abscesses. The difference in $T_{2}$ is related to the material content of samples.

Dentomaxillofacial Radiology (2012) 41, 385-391. doi: 10.1259/dmfr/96188015

Keywords: magnetic resonance; $T_{1} ; T_{2}$; jaw cysts; abscesses

\section{Introduction}

MRI is known to be a conventional diagnostic tool in medicine. MR films compare contrasts obtained for different fluids, organs or masses for diagnostic purposes. The comparison differentiates healthy and pathological situations through the appearance of images which are caused by different signal intensities. ${ }^{1-3}$ In such cases, the detailed information is qualitatively produced only by hypo and hyper-signal intensities. In parallel with the use of MRI in medicine, some in vitro $T_{1}$ and $T_{2}$ measurements in fluids (or solutions) were carried out by nuclear magnetic resonance (NMR) spectroscopy in order to get the relevant information for obtaining the

\footnotetext{
*Correspondence to: Dr U Nezih Yilmaz, Department of Oral and Maxillofacial Surgery, Faculty of Dentistry, University of Dicle, 21280 Diyarbakır, Turkey. E-mail: utkunezih@dicle.edu.tr

Received 3 January 2011; revised 26 April 2011; accepted 4 May 2011
}

best MR images. ${ }^{4-7}$ Besides this, the phantom imaging of body fluids (or solutions), organs and other complementary measurements using MRI have been used together to acquire detailed information for image analysis or image interpretation. ${ }^{8-15}$ In the latter case, the cause of contrast is quantitatively determined. The number of such complementary studies is not limited to the references given here. One might find numerous papers published for these purposes.

MR images of maxillary cysts and abscesses have been reported in a large number of studies. ${ }^{1-3,8,9,14-26}$ Qualitative MR information was mostly obtained through hypo (low) and hyper (high) signal intensities of those images. ${ }^{1-3,19,23-26}$ In two studies, differentiation of hepatic malignancies from cysts was made using a $T_{2}$ or $T_{1} / T_{2}$ ratio, while distinction of the odontogenic keratocysts from other cysts and ameloblastoma was 
made by $T_{2}$ in another study. ${ }^{15,16,22}$ However, a comparison between MR relaxation times of jaw cysts and abscesses has not yet been made. Also, the cause of MR contrast is not quantitatively determined for such cases. A phantom study comparing the relaxation times of cysts and abscesses, and also determining reasons for MR contrast, should be a complementary work and it should be useful for MR image interpretation.

One aim of this study was to find out the comparison of the relaxation times in cysts and abscesses, while the other was to obtain dependencies of the relaxation rates $\left(1 / T_{1}\right.$ and $\left.1 / T_{2}\right)$ on water-free material contents of samples. For these purposes, the relaxation times in cystic fluids and abscesses were measured by MR. The water free-material content of each sample was determined by dehydration. The data of groups were compared statistically.

\section{Materials and methods}

\section{Cysts and abscesses}

20 odontogenic cystic fluids and 11 abscesses were collected from patients with jaw cysts and abscesses before surgical operation. Each fluid was carefully aspirated from the lesion of the jaw region and immediately transferred into a covered tube. Particular attention was paid to the sample transfer in order to leave minimal contamination in the injectors. Each tube was then sealed using Parafilm "M" (Pechiney Plastic Packing, Chicago, IL) to prevent water loss and placed in a capped plastic container and stored in a refrigerator at $-2{ }^{\circ} \mathrm{C}$. During phantom preparation, each sample was shaken gently to make the samples homogeneous. $3 \mathrm{ml}$ of samples were then carefully transferred into tubes in the phantom. The inlet of each tube in the phantom and the whole phantom were sealed using parafilm. The phantom was then brought to the MRI facility in a Dewar Flask (KGW-Isotherm, Karlsruhe, Germany) containing dry ice in closed plastics. Even if the sedimentation rate for the material in the fluids was very low, the phantom was shaken gently before replacing it in the MR machine. The fluids were diagnosed on the basis of radiological and histopathological findings and they were treated as two groups: cysts and abscesses.

Water free-material contents of cysts and abscesses per $1 \mathrm{ml}$ of samples

$1 \mathrm{ml}$ of each sample was replaced in a weighted glass tube. The water free-material content of each sample was determined by weighing the tube containing the sample before and after drying at $120^{\circ} \mathrm{C}$ for $24 \mathrm{~h} .{ }^{27,28}$

\section{Relaxation measurements}

Cysts and abscesses were transferred into cylindrical glass tubes $(1.2 \mathrm{~cm}$ diameter and $10 \mathrm{~cm}$ height), which were placed in a plastic phantom. The sample volume was $3 \mathrm{ml}$.

The phantom was imaged by $1.5 \mathrm{~T}$ MR scanners (Philips Medical Systems, Intera, Netherlands) at a room temperature of $20-22^{\circ} \mathrm{C}$ using a head coil. The field of view (FOV) was $160 \times 160 \mathrm{~mm}$ and the acquisition matrix was $256 \times 256$. Images with a slice thickness of $15 \mathrm{~mm}$ were reconstructed using a two-dimensional fourier transform (2D-FT) technique. $T_{1}$ measurements were then performed by using a mixed sequence where an inversion recovery (IR) and a spin-echo (SE) were consecutively combined in one cycle. ${ }^{29-31} \mathrm{SE}$ and IR pulse repetition times $\left(T R_{S E}\right.$ and $\left.T R_{I R}\right)$ were chosen as $7000 \mathrm{~ms}$ and $8000 \mathrm{~ms}$, respectively, to allow a full recovery of magnetization, whereas the delay time $\left(\mathrm{T}_{\mathrm{I}}\right)$ between the $180^{\circ}$ and $90^{\circ}$ pulses of the IR part of the mixed sequence was $1000 \mathrm{~ms}$. $T_{2}$ measurements were carried out by the Carr-Purcell Meiboom-Gill (CPMG) pulse sequence with eight-echoes. In this case, the pulse repetition time (TR) was set at $7000 \mathrm{~ms}$ and echo delays (TEs) were increased stepwise from $30 \mathrm{~ms}$ to $240 \mathrm{~ms}$ in increments of $30 \mathrm{~ms}$. The $T_{1}$ and $T_{2}$ maps of the phantoms are shown in Figures 1 and 2, respectively.

\section{Statistical evaluations}

The groups were compared statistically by using the statistical package Medcalc version 10.3.0.0 for Windows (Medcalc Software bvba, Ghent, Belgium). The data were expressed as a category mean \pm standard deviation (SD). The differences among the mean values of all categories were tested first by one- way analysis of variance (ANOVA), followed by the Student-NewmanKeuls test for multiple comparisons. ${ }^{32-34}$ The significance level for the difference between the groups was ascertained at $p<0.05$.

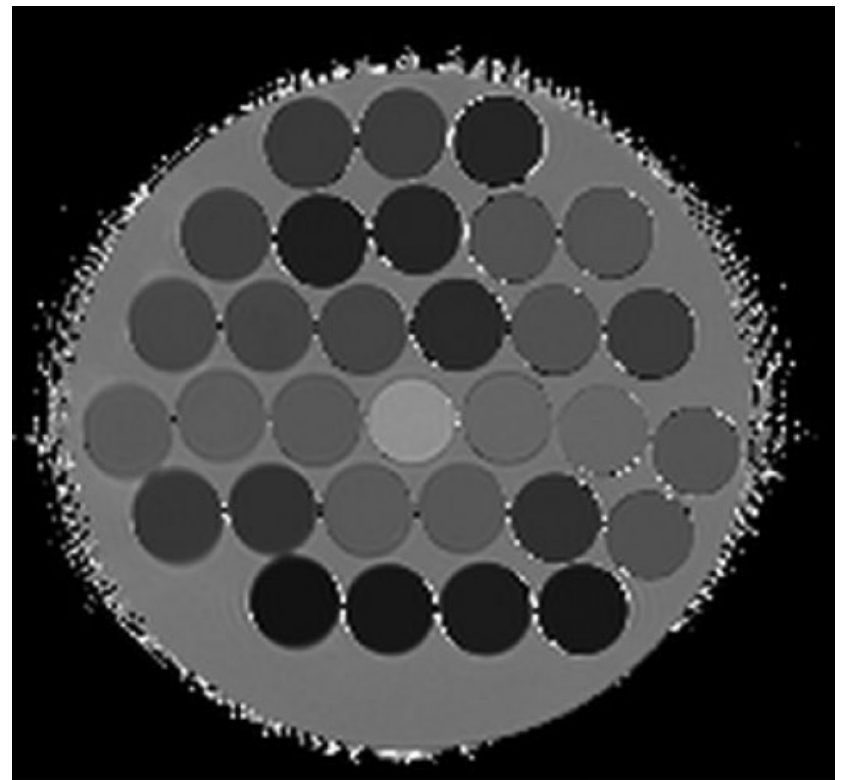

Figure $1 T_{1}$ map of cysts and abscesses. Top to bottom: second and third rows show abscesses and other rows show cysts 


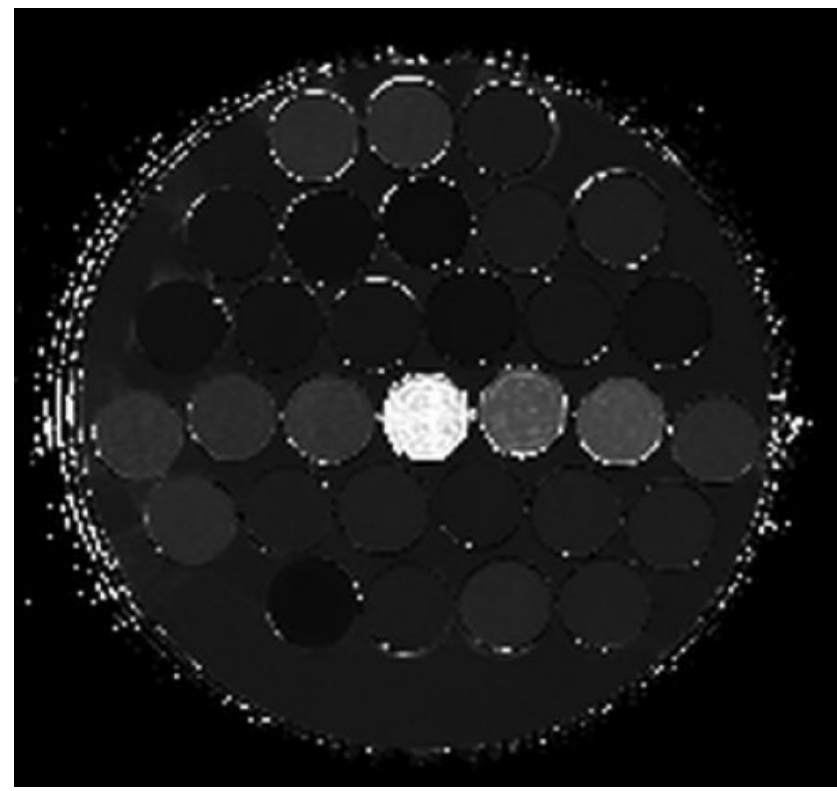

Figure $2 T_{2}$ map of cysts and abscesses. Top to bottom: second and third rows show abscesses and other rows show cysts

\section{Results}

The mean values of the $1 / T_{1}$ and $1 / T_{2}$ in different groups are given in Table 1 together with SD. The mean $1 / T_{1}$ in cysts and abscesses are $0.9355 \mathrm{~s}^{-1}$ and $0.8245 \mathrm{~s}^{-1}$, respectively. The mean $1 / T_{2}$ was $2.4575 \mathrm{~s}^{-1}$ for cysts and $4.7073 \mathrm{~s}^{-1}$ for abscesses.

The statistical evaluation reveals that the $1 / T_{1}$ in cysts is not significantly different compared with that in abscesses $(p=0.4683)$. However, the $1 / T_{2}$ in cysts is very highly significantly different from that in abscesses $(p=0.0001)$. The comparisons are also given in Figure 3 for $T_{1}$ and in Figure 4 for $T_{2}$. A confidence interval (CI) of $95 \%$ for $T_{2}$ of cysts does not overlap that of abscesses but both CI regarding $T_{1}$ overlap each other.

The $1 / T_{1}$ and $1 / T_{2}$ vs the water-free content of cysts and abscesses are shown in Figures 5 and 6, respectively. Both cysts and abscesses give a moderate correlation with material contents. Correlation coefficients for cysts $\left(0.6668\right.$ for $T_{1}$ and 0.6972 for $\left.T_{2}\right)$ are higher than those for abscesses $\left(0.6103\right.$ for $T_{1}$ and 0.6186 for $T_{2}$ ). This is consistent with previous data expressing the relaxation rates in jaw cysts as the product of total relaxivity and total material content. ${ }^{18}$ Each linearity, indicated in Figures 5 and 6, is also consistent with those given for cysts and other similar works. $4,17,18,27,28$
The slope of each line in Figures 5 and 6 denotes the incremental increase in the relaxation rate per unit concentration of dry material which is termed as relaxivity. ${ }^{4} T_{2}$ relaxivities $\left[26.458 \mathrm{ml}(\mathrm{g} \mathrm{s})^{-1}\right.$ for abscesses and $21.455 \mathrm{ml}\left(\mathrm{g} \mathrm{s}^{-1}\right.$ for cysts] are higher than $T_{1}$ relaxivities $\left[5.4766 \mathrm{ml}(\mathrm{g} \mathrm{s})^{-1}\right.$ for abscesses and $10.075 \mathrm{ml}\left(\mathrm{g} \mathrm{s}^{-1}\right.$ for cysts]. Higher $T_{2}$ relaxivities are consistent with the literature. ${ }^{4,18,20,21}$ The relatively higher $T_{2}$ relaxivity of cysts is also consistent with the significant difference between the $T_{2}$ of cysts and abscesses.

\section{Discussion}

Medical examinations by MRI require a separate image for each patient. Gathering such images for one or two groups of patients takes months. During this period, choices for operator dependent parameters, artefacts caused by patient motions and the use of different machines affect the image quality. ${ }^{35-38}$ Therefore, MR images obtained at different times or by different machines are not suitable for a reliable scientific estimation. Also, such clinical studies do not provide quantitative information. However, in the phantom study, the several samples were replaced in a phantom for each type of disease. The procedures used for sample collection, storage and phantom preparation is assumed not to have a significant effect on the experiment if they were applied carefully. ${ }^{39,40}$ Operator dependent parameters were the same for all samples since all of them are imaged simultaneously. Therefore, phantom studies should be more convenient for a comparison of a large number of MR images.

The highly significant difference $(p=0.001)$ between the $T_{2}$ values of cysts and abscesses (Table 1 ) indicates that in vitro $T_{2}$ measurements may differentiate cysts from abscesses for a confidence interval (CI) of $95 \%$. This differentiation is also demonstrated in Figure 4. In this figure, the upper borders of boxes show the mean values of $1 / T_{2}$, whereas the vertical lines represent the CI for the mean values. The relevant $1 / T_{2}$ values of cysts distribute along the left vertical line, whereas those of abscesses distribute along the right vertical line. The discreteness between vertical lines is about $0.756 \mathrm{~s}^{-1}$ and it displays the differentiation. This means that $1 / T_{2}$ values for $95 \%$ of the cystic fluids are different from those for $95 \%$ of the abscesses. Knowledge of such a difference is a very valuable for diagnosis. In MRI, the image contrast is only dependent on three intrinsic independent parameters: (i) the spin density, (ii) the spin-lattice relaxation time $T_{1}$ and (iii) the spin-spin

Table 1 Comparison of the mean relaxation rates $\left(1 / T_{1}\right.$ and $\left.1 / T_{2}\right)$ in cysts and abscesses. $p<0.05$ denotes a significant difference between the two groups

\begin{tabular}{lllll}
\hline Groups & $1 / \mathrm{T}_{1}\left(s^{-1}\right)$ & $\mathrm{p}$-value & $1 / \mathrm{T}_{2}\left(s^{-1}\right)$ & $\mathrm{p}$-value \\
\hline Cysts & $0.9355 \pm 0.5893$ & 0.4863 & $2.4575 \pm 1.2291$ & 0.0001 \\
Abscesses & $0.8245 \pm 0.2851$ & 0.4863 & $4.7073 \pm 1.3679$ & 0.0001 \\
\hline
\end{tabular}




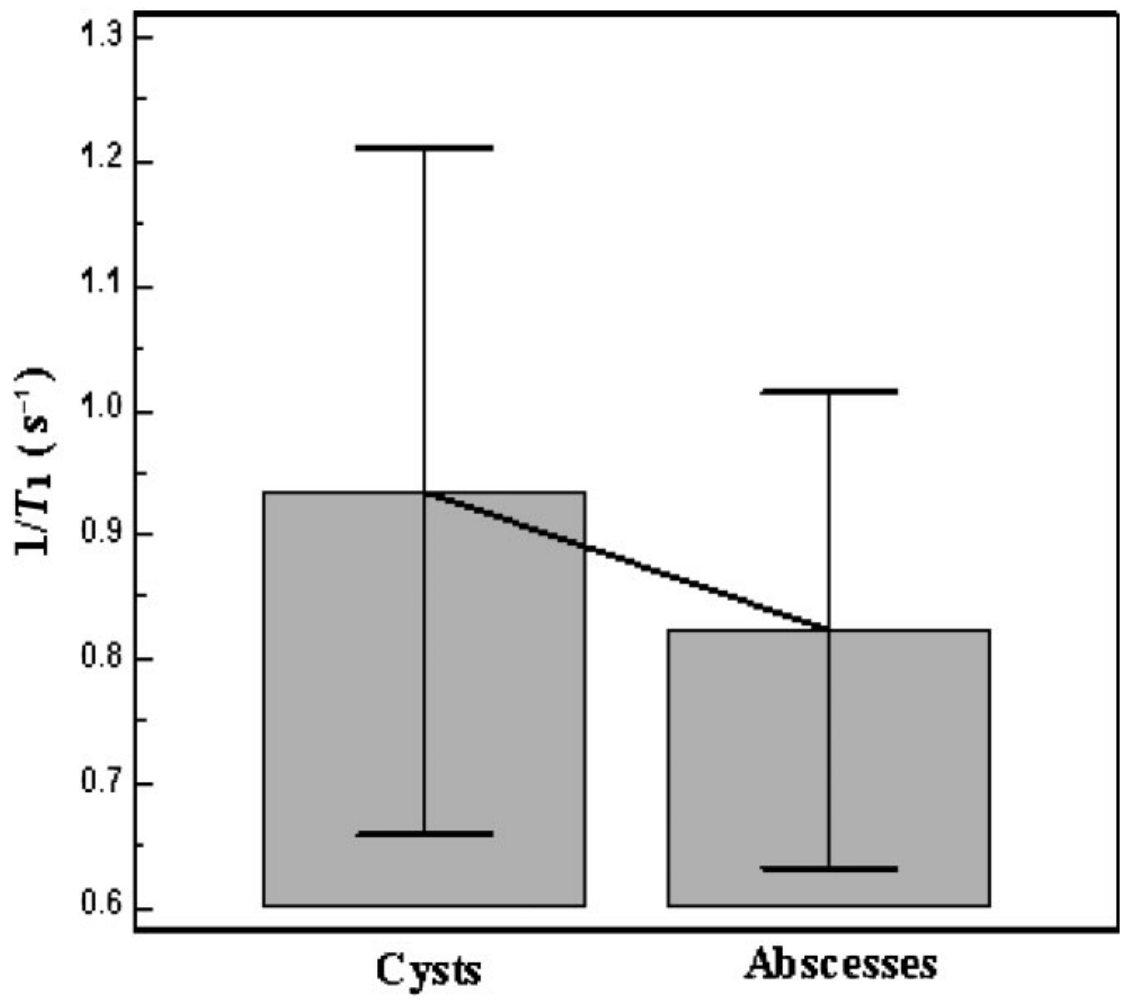

Figure 3 Comparison of the $1 / T_{1}$ in cysts and abscesses for a confidence interval (CI) of $95 \%$. The upper borders of the left and right boxes show the mean values of $1 / T_{1}$ for cysts and abscesses, respectively. The vertical lines represent the relevant CI. A large part of the CI for cysts overlaps that of abscesses. It means that $1 / T_{1}$ values of a significant amount of cysts overlap those of abscesses

relaxation time $T_{2} \cdot{ }^{29,35}$ Because in vivo and in vitro image contrasts of fluids and masses are changed by the same parameters, the $T_{2}$ findings obtained by the phantom imaging should be valid for in vivo MRI. Accordingly, in vivo $T_{2}$-weighted images of jaw cysts should be different from those of abscesses. Hence the differences given in Table 1 may provide statistical information for clinicians and researchers making MRI analysis.

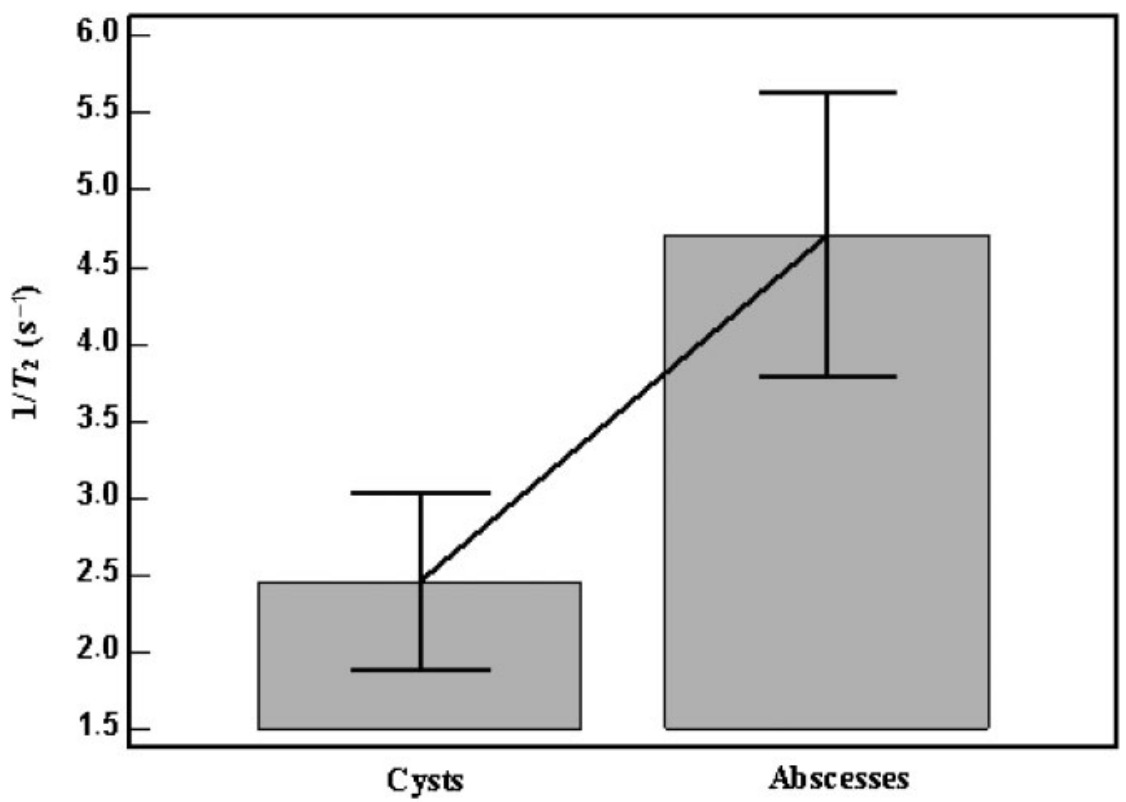

Figure 4 Comparison of the $1 / T_{2}$ in cysts and abscesses for a confidence interval (CI) of $95 \%$. The upper borders of the left and right boxes show the mean values of $1 / T_{2}$ for cysts and abscesses, respectively. The vertical lines represent the relevant CI. The CI for cysts is completely discrete from that of abscesses. This means that $1 / T_{2}$ values for $95 \%$ of cysts are different to that for $95 \%$ of abscesses 


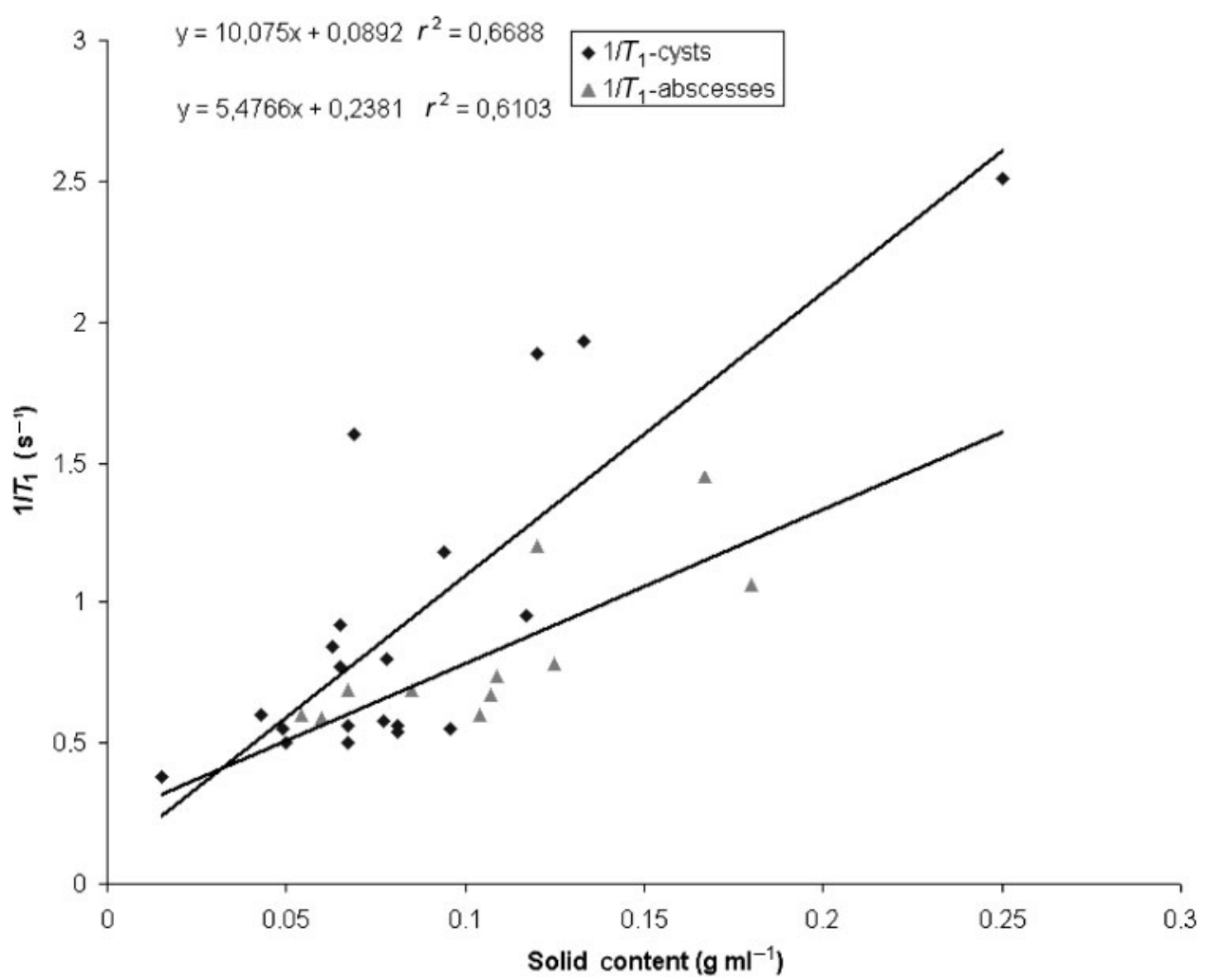

Figure 5 The least square fits of the $1 / T_{1}$ in cysts and abscesses $v s$ dry solid content. Squares and triangles denote cysts and abscesses, respectively

The relaxation of a fluid associated with material content is written as $\mathrm{N}_{\mathrm{b}} 1 / \mathrm{T}_{\mathrm{ib}} \mathrm{C}(\mathrm{i}: 1,2) . \mathrm{N}_{\mathrm{b}}, 1 / \mathrm{T}_{\mathrm{ib}}$ and $\mathrm{C}$ denote the number of bound water, the relaxation rates of bound water and concentration of dry solid material, respectively. ${ }^{35}$ The relaxation in a natural sample is proportional to its dry material content. This means that $\mathrm{C}$ is a significant source of contrast. In fact, the darkest three images in Figure 2 belong to the samples with the highest material content $\left(>0.15 \mathrm{~g} \mathrm{ml}^{-1}\right)$ while the brightest three images belong to the samples with the lowest material content $\left(<0.05 \mathrm{~g} \mathrm{ml}^{-1}\right)$. Other images can also be related to the content of fluids.

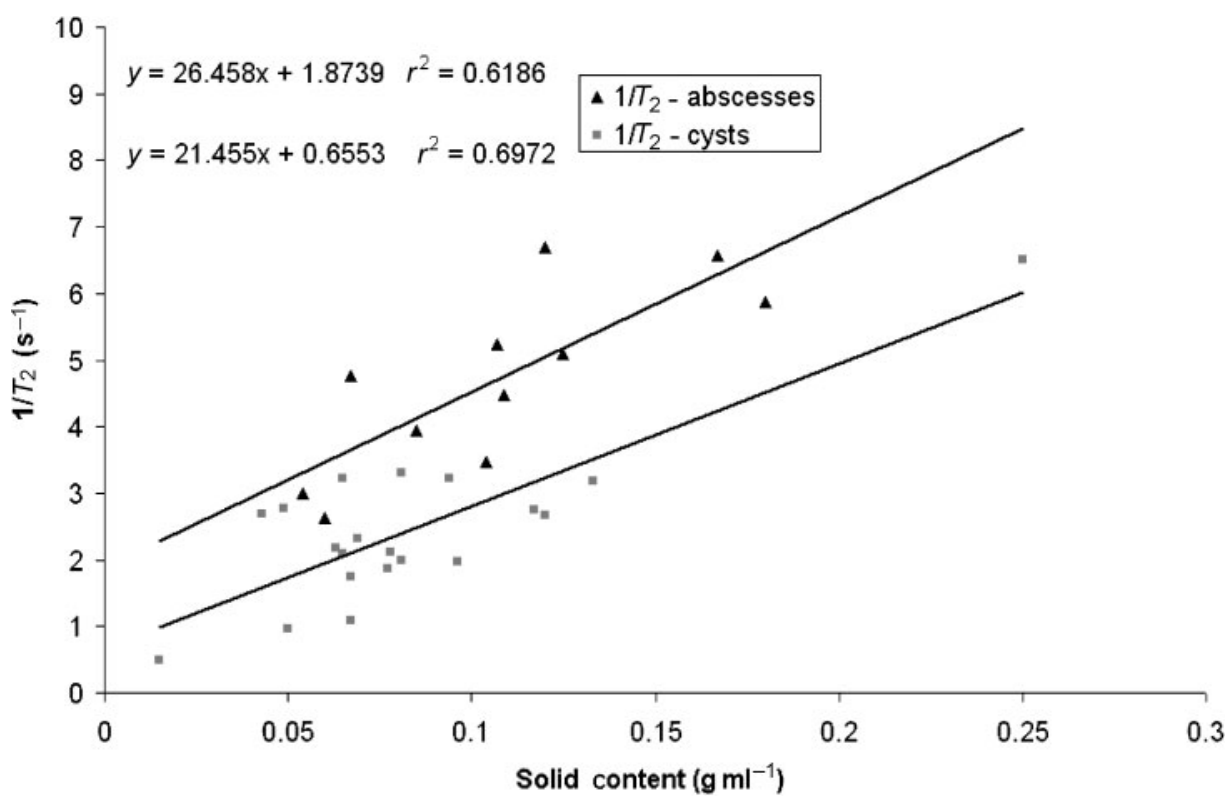

Figure 6 The least square fits of the $1 / T_{2}$ in cysts and abscesses $v s$ dry solid content. Squares and triangles denote cysts and abscesses, respectively 
The cause of contrasts seen in Figure 2 is given in Figure 6. Accordingly, the relationship between dry material content and the relaxation rates, indicated in Figures 5 and 6 , provide quantitative information for the image contrast. According to Figure 6, this information is about $70 \%$ for cysts and $62 \%$ for abscesses. Since such information is related to MR contrast and since in vitro findings are most likely valid for in vivo studies, the relationships in Figure 6 should provide quantitative information for the source of MR contrast, which is useful for the image interpretation and further investigations.

The relaxivity is known to expresses the efficiency of a material to alter the relaxation times. ${ }^{4,18}$ According to Figures 5 and $6, T_{2}$ is more efficiently altered by dry solids than the $T_{1}$. Also, the dry solids in abscesses are much more effective than those in cysts in altering the $T_{2}$ relaxation times. This is consistent with findings given in

\section{References}

1. Billeci D, Marton E, Tripodi M, Orvieto E, Longatti P. Symptomatic Rathke's cleft cysts: a radiological, surgical and pathological review. Pituitary 2004; 7: 131-137.

2. Kuratomi Y, Satoh S, Hayashida S, Inokuchi A. Basal cell adenoma and lymphoepithelial cyst as recurrent tumors of pleomorphic adenoma of the parotid gland. Auris Nasus Larynx 2006; 33: 7-100.

3. Ahn JY, Kang SY, Lee CH, Yoon PH, Lee KS. Parapharyngeal branchial cleft cyst extending to the skull base: a lateral transzygomatic-transtemporal approach to the parapharyngeal space. Neurosurg Rev 2005; 28: 73-76.

4. Kang, YS, Gore JC, Armitage IM. Studies of factors affecting the design of NMR contrast agents: manganese in blood as a model system. Magn Reson Med 1984; 1: 396-409.

5. Brooks RA, Vymazal J, Bulte JW, Baumgarner CD, Tran V. Comparison of T2 relaxation in blood, brain, and ferritin. $J$ Magn Reson Imaging 1995; 5: 446-450.

6. Gossuin Y, Muller RN, Gillis BL. Relaxivities of human liver and spleen ferritin. Magn Reson Imaging 2005; 23: 1001-1004.

7. Ghugre NR, Coates TD, Nelson MD, Wood JC. Mechanisms of tissue-iron relaxivity: nuclear magnetic resonance studies on human liver biopsy specimens. Magn Reson Med 2005; 54: 1185-1193.

8. Gomori JM, Horev G, Tamary H, Zandback J, Kornreich L, Zaizov R, et al. Hepatic iron overload: quantitative MR imaging. Radiology 1991; 179: 367-369.

9. Ahmadi J, Destian S, Apuzzo MLJ, Segall HD, Zee CS. Cystic fluid in craniopharyngiomas: MR imaging and quantitative analysis. Radiology 1992; 182: 783-785.

10. Timmer FA, Sluzewski M, Treskes M, Van Rooij WJJ, Teepen JLJM, Wijnalda D. Chemical analysis of an epidermoid cyst with unusual CT and MR characteristics. AJNR Am J Neuroradiol 1998; 19: 1111-1112.

11. Isokawa $\mathbf{M}$, Kimura $\mathrm{F}$, Matsuki $\mathrm{T}$, Omoto $\mathrm{E}$, Otsuka $\mathrm{K}$, Kurokawa $\mathrm{H}$, et al. Evaluation of bone marrow iron by magnetic resonance imaging. Ann Hematol 1997; 74: 269-274.

12. Anderson LJ, Holden S, Davis B, Prescott E, Charrier CC, Bunce $\mathrm{NH}$, et al. Cardiovascular $T_{2}$-star $\left(T_{2}{ }^{*}\right)$ magnetic resonance for the early diagnosis of myocardial iron overload. Eur Heart $J$ 2001; 22: 2171-2179.

13. Hakansson K, Christoffersson JO, Leander P, Ekberg O, Hakansson HO. On the appearance of bile in clinical MR cholangiopancreatography. Acta Radiol 2002; 43: 401-410.

14. Takahashi K, Okada S, Okada M, Kitao M, Kaji Y, Sugimura K. Magnetic resonance relaxation time in evaluating the cyst fluid characteristics of endometrioma. Hum Reprod 1996; 11: 857-860.
Table 1, revealing the discrimination of cysts from abscesses by $T_{2}$. Given that relaxivities are used for diagnostic purposes, the current figures should supply complementary information for MR image analysis and further research. ${ }^{20,21}$

In conclusion, current data implies that $T_{2}$ measurements may differentiate jaw cysts from jaw abscesses. Also, the data show that the relaxation rates are correlated to dry material content. Both findings may provide quantitative information for clinicians making image analysis.

\section{Acknowledgments}

The authors thank Professor Ali Yilmaz of Dicle University, who improved the English in this paper and made helpful discussions with the authors regarding physical interpretations.
15. Farraher SW, Jara H, Chang KJ, Ozonoff A, Soto JA. Differentiation of hepatocellular carcinoma and hepatic metastasis from cysts and hemangiomas with calculated $T_{2}$ relaxation times and the $T_{1} / T_{2}$ relaxation times ratio. $J$ Magn Reson Imaging 2006; 24: $333-341$.

16. Minami M, Kaneda T, Ozawa K, Yamamoto H, Itai Y, Ozowa $\mathrm{M}$, et al. Cystic lesions of the maxillomandibular region: MR imaging distinction of odontogenic keratocysts and ameloblastomas from other cysts. AJR Am J Roentgenol 1996; 166: 943-949.

17. Erol B, Yilmaz UN, Tanrikulu R, Yilmaz A. Determinants of MR relaxation rates in jaw cysts: implications for diagnostic values of the relaxation times. Dentomaxillofac Radiol 2004; 33: 183-187.

18. Yilmaz UN, Rezzan G, Erol B. Total relaxivities of the material content in various cysts and ameloblastoma: implications for discriminating different fluids. Biol Trace Elem Res 2010; 133: 144-152.

19. Matsuzaki H, Asaumi J, Yanagi Y, Konouchi H, Honda Y, Hisatomi M, et al. MR imaging in the assessment of a solitary bone cyst. Eur J Radiol 2003; 45: 137-142.

20. Kawamata A, Xiao Na Z, Fujiki Y. Gd-DTPA enhanced MRI for the oral and maxillofacial cystic lesion. Oral Radiol 1992; 8: 33-39.

21. Yanagi Y, Asaumi J, Unetsubo T, Ashida M, Takenobu T, Hisatomi M, et al. Usefulness of MRI and dynamic contrastenhanced MRI for differential diagnosis of simple bone cysts from true cysts in the jaw. Oral Surg Oral Med Oral Pathol Oral Radiol Endod 2010; 110: 364-369.

22. Olcott EW, Li KCP, Wright GA, Pattarelli PP, Katz DZ, Ch'en IY, et al. Differentiation of hepatic malignancies from hemangiomas and cysts by $T_{2}$ relaxation times: early experience with multiply refocused four-echo imaging at $1.5 \mathrm{~T}$. J Magn Reson Imaging 1999; 9: 81-86.

23. Kashiwagi N, Fujita N, Hirabuki HN, Tanaka N, Sato T, Sato M, et al. MR findings in three pituitary abscesses. Acta Radiol 1998; 39: 490-493.

24. Cem BN, Semelka RC, Noone TC, Siegelman ES, de Beeck BO, Brown JJ, et al. Pyogenic hepatic abscesses: MRI findings on $T_{1}$ and $T_{2}$-weighted and serial gadolinium-enhanced gradient-echo images. J Magn Reson Imaging 1999; 9: 285-290.

25. Feyza KG, Serdar B, Sencer A, Emel E, Hamamcioglu K, Özkan $\mathrm{N}$, et al. Posterior fossa dermoid cysts causing cerebellar abscesses. Pediatr Neurosurg 2007; 43: 323-326.

26. Hasegawa T, Shibuya Y, Kuroki S, Takeuchi J, Yokoo S, Umeda $\mathrm{M}$, et al. Two cases of masticator space abscess initially diagnosed as temporomandibular joint disorder. Kobe J Med Sci 2008; 54: E163-E168. 
27. Koivula A, Suominen K, Timonen T, Kiviniitty K. The spinlattice relaxation time in the blood of healthy subjects and patients with malignant blood disease. Phys Med Biol 1982; 27 : 937-947.

28. Cameron IL, Ord VA, Fullerton GD. Water of hydration in the intra-and extra-cellular environment of human erythrocytes. Magn Reson Med 1988; 66: 1186-1199.

29. In den Kleef JJ, Cuppen JJ. RLSQ: $T_{1}, T_{2}$ and rho calculations, combining ratios and least squares. Magnet Reson Med 1987; 5: 513-24.

30. Jensen ME, Caruthers SD, Jara H. Quantitative magnetic resonance imaging with the mixed turbo spin-echo pulse sequence. A validation study. The Internet Journal of Radiology [serial on the internet]. 2001. Available from: http://www.ispub.com/journal/the-internet-journal-of-radiology/volume2-number-1/quantitative-magnetic-resonance-imaging-with-themixed-turbo-spin-echo-pulse-sequence-a-validation-study.html

31. Breuseghem IV, Bosmans HTC, Elst LV, Maes F, Pans SD, Brys PPMA, et al. $T_{2}$ mapping of human femorotibial cartilage with turbo mixed MR imaging at 1.5 T: feasibility. Radiology 2004; 233: 609-6141.

32. Wichi R, Malfitano C, Rosa K, De Souza SB, Salemi V, Mostarda $\mathrm{C}$, et al. Noninvasive and invasive evaluation of cardiac dysfunction in experimental diabetes in rodents. Cardiovasc Diabetol 2007; 6: 14
33. Kaoa C-T, Dingb S-J, Hec H, Choud MY, Huangd T-S. Cytotoxicity of orthodontic wire corroded in fluoride solution in vitro. Angle Orthod 2007; 77: 349-354.

34. Wang Y, Corr JG, Tao Y, Fair WR, Heston WDW. Decreased growth of established human prostate $\mathrm{LNCaP}$ tumors in nude mice fed a low-fat diet. J Natl Cancer Inst 1995; 87: 1456-1462.

35. Stark DD, Bradley WG. Magnetic resonance imaging. St Louis, MO: The C.V. Mosby Company; 1988.

36. Hendrick RE. Sampling time effects on signal-to-noise and contrastto-noise ratios in spin-echo MRI. Magn Reson Imaging 1987; 5: 31-37.

37. Stadler A, Schima W, Ba-Ssalamah A, Kettenbach J, Eisenhuber E. Artifacts in body MR imaging: their appearance and how to eliminate them. Eur Radiol 2007; 17: 1242-1255.

38. Ihalainen T, Sipilä O, Savolainen S. MRI quality control: six imagers studied using eleven unified image quality parameters. Eur Radiol 2004; 14: 1859-1865.

39. De Certaines J, Bernard AM, Benoist L, Rivet P, Gallier J, Morin P. Nuclear magnetic resonance study of cancer: systemic effect on the proton relaxation times $\left(T_{1}\right.$ and $\left.T_{2}\right)$ of human serum. Cancer Detect Prev 1981; 4: 267-271.

40. Schuhmacher JH, Conrad D, Manke HG, Clorius JH, Matys ER, Hauser $\mathrm{H}$, et al. Investigations concerning the potential for using 1h NMR relaxometry or high-resolution spectroscopy of plasma as a screening test for malignant lung disease. Magn Reson Med 1990; 13: 103-132. 